\title{
Rechtsbescherming
}

\section{PPU, PPA en behandeling met voorrang. Drie mechanismen voor een snellere behandeling van prejudiciële verwijzingen}

\author{
Mr. J.R.K.A.M. Waasdorp*
}

Het Hof van Justitie behandelt een prejudiciële verwijzing in beginsel volgens de standaardprocedure. Als de zaak noopt tot een snellere afdoening, dan kan echter van deze procedure worden afgeweken. Zo kan de president van het Hof van Justitie op verzoek van de nationale rechter of ambtshalve beslissen de spoed- of de versnelde procedure toe te passen of een prejudiciële verwijzing met voorrang te behandelen. Dit artikel biedt een overzicht van deze afwijkingen van de standaardprocedure.

\section{Inleiding}

In artikel 267 VWEU is de bevoegdheid van het Hof van Justitie opgenomen om bij wijze van prejudiciële beslissing een uitspraak te doen over de uitleg van EUrecht en over de geldigheid en uitleg van handelingen van de instellingen, organen of instanties van de Europese Unie. Deze bevoegdheid mag het Hof van Justitie alleen gebruiken als de nationale rechter dat verzoekt. ${ }^{1}$ Dat doet die rechter met een zogeheten prejudiciële verwijzing. Daarin stelt hij één of meer vragen over de uitlegging of geldigheid van Unierecht. ${ }^{2}$

Het Hof van Justitie behandelt een prejudiciële verwijzing als hoofdregel volgens de standaardprocedure.

* Mr. J.R.K.A.M. (Jim) Waasdorp is werkzaam als jurist bij de Onderzoeksdirectie van het Hof van Justitie van de Europese Unie en is daarnaast buitenpromovendus bij de Universiteit Utrecht. Deze bijdrage is op persoonlijke titel geschreven. De tekst is afgesloten op 19 december 2018. Nadien zijn nog enkele tekstuele wijzigingen aangebracht.

1. HvJ 6 april 1962, zaak 13/61, De Geus en Uitdenbogerd, ECLI:EU:C: 1962:11, Jur. 1962, p. 103-104.

2. Zie voor achtergrondinformatie over de prejudiciële procedure: K. Lenaerts e.a., EU Procedural Law, Oxford: Oxford University Press 2014, p. 783-797; S. Prechal en R.J.G.M. Widdershoven (red.), Inleiding tot het Europees bestuursrecht, Nijmegen: Ars Aequi Libri 2017, p. 345-356.
Deze procedure is neergelegd in de artikelen 93 tot en met 104 van het Reglement voor de procesvoering (hierna: Reglement). Artikel 23bis van het Statuut van het Hof van Justitie (hierna: Statuut) bepaalt evenwel dat het Reglement kan voorzien in een spoedprocedure (procédure préjudicielle d'urgence; $P P U$ ) en een versnelde procedure (procedure préjudicielle accélérée; $P P A$ ). De eerstbedoelde procedure is te vinden in artikel 53 lid 5 en de artikelen 107 tot en met 114 van het Reglement. De versnelde procedure is opgenomen in artikel 53 lid 4 en de artikelen 105 en 106. Tot slot kan een prejudiciële verwijzing met voorrang worden behandeld (traitement prioritaire). Dit is bepaald in artikel 53 lid 3 van het Reglement. Deze drie mechanismen zijn de voornaamste gereedschappen om de behandeling van een prejudiciele verwijzing te versnellen. ${ }^{3}$

De president van het Hof van Justitie kan op verzoek van de nationale rechter of ambtshalve beslissen een van deze drie mechanismen toe te passen. Voor de nationale rechter is het nuttig om te weten in welke gevallen hij een dergelijk verzoek kan doen. Daarom analyseer ik in deze bijdrage welke criteria worden gehanteerd bij de beslissing tot toepassing van de spoedprocedure, de versnelde procedure en behandeling met voorrang.

\section{PPU: de spoedprocedure}

\section{Kenmerken ${ }^{4}$}

De spoedprocedure bestaat sinds 1 maart 2008 en kan slechts worden toegepast op een prejudiciële verwijzing

3. M. Wathelet, 'Accelerated Procedures Before the Court of Justice of the European Union', in: K. Bradley e.a. (red.), Of Courts and Constitutions: Liber Amicorum in Honour of Nial Fennelly, Oxford: Hart Publishing 2014, p. 33 en 45.

4. Zie uitgebreider: A. Łazowski, Urgent preliminary Ruling Procedure (European Current Law), Londen: Thomson Reuters 2009, p. xvii-xxi; Wathelet 2014, p. 37-45; S. Bartolini, 'The Urgent Preliminary Ruling Procedure: Ten Years On', European Public Law 2018, p. 215-217. 
die betrekking heeft op de gebieden bedoeld in titel $\mathrm{V}$ van het derde deel VWEU. Het gaat hier om de ruimte van vrijheid, veiligheid en recht. Voor de uitleg van Unierecht dat hiertoe niet behoort, kan deze procedure dus niet worden toegepast. ${ }^{5}$

Als de nationale rechter verzoekt om toepassing van de spoedprocedure, dan is hij verplicht in zijn verwijzingsbeslissing alle omstandigheden, rechtens en feitelijk, uiteen te zetten die de spoed aantonen en de toepassing van de spoedprocedure rechtvaardigen. ${ }^{6}$ Vervolgens is het aan de president van het Hof van Justitie om op dit verzoek te beslissen. Zo nodig kan de nationale rechter om verduidelijking worden verzocht (art. 101 lid 1 van het Reglement). Het betreft een verduidelijking van de feitelijke en juridische situatie van de zaak, zodanig dat een beslissing op het verzoek kan worden genomen. ${ }^{7}$ Daarnaast kan de president de spoedprocedure ambtshalve toepassen.

In zijn algemeenheid kan niet worden aangegeven wanneer sprake is van spoed. Uit de jurisprudentie van het Hof van Justitie kan echter wel worden opgemaakt dat het moet gaan om situaties waarin de op het spel staande rechten en belangen onherstelbaar door tijdsverloop kunnen worden geschaad. In een dergelijk geval kan de nationale rechter de gemiddelde duur van de standaardprocedure niet afwachten. ${ }^{8}$ Gedacht moet worden aan zaken over gedetineerde personen (art. 267 lid 4 VWEU; zie hierna paragraaf Straf-en bestuursrechtelijke vrijheidsontneming). Daarnaast kan de spoedeisendheid zijn gelegen in het bestaan van een risico op onherstelbare beschadiging van de betrekkingen tussen kind en ouder (zie hierna paragraaf Risico op onherstelbare beschadiging van de betrekkingen tussen kind en ouder). In beide gevallen geldt dat het antwoord op de gestelde prejudiciële vragen relevant moet zijn voor de uitkomst van de nationale procedure. ${ }^{9}$ Tot slot laat recente jurisprudentie zien dat het Hof van Justitie ook in andere omstandigheden bereid is de spoedprocedure toe te passen (zie hierna paragraaf Overige omstandigheden).

Straf- en bestuursrechtelijke vrijheidsontneming Het is vaste jurisprudentie van het Hof van Justitie dat bij de beoordeling van de spoedeisendheid rekening moet worden gehouden met de omstandigheid dat de betrokkene in het hoofdgeding zijn vrijheid is ontnomen

5. HvJ 24 oktober 2013, zaak C-369/13, Gielen e.a., ECLI:EU:C:2015:85, punt 8; HvJ 6 mei 2014, zaak C-181/14, G, ECLI:EU:C:2014:740, punt 8.

6. Zie de conclusie van A-G Sharpston van 9 juli 2012, zaak C-278/12 PPU, Adil, ECLI:EU:C:2012:430, punt 33.

7. Bijv. HvJ 16 februari 2017, zaak C-578/16 PPU, C.K. e.a., ECLI:EU:C: 2017:127, punt 50; HvJ 14 september 2017, zaak C-18/16, ECLI:EU:C: 2017:680, K., punten 29 en 30.

8. Ontleend aan Bartolini 2018, p. 215. Vgl. Wathelet 2014, p. 45. In 2017 bedroeg de gemiddelde duur 16,3 maand. Zie het verslag van het Hof van Justitie over het jaar 2017, p. 5 en 37 (via www.curia.europa. eu).

9. Vgl. Aanbevelingen aan de nationale rechterlijke instanties over het aanhangig maken van prejudiciële procedures (2016/C 439/01), punt 33. Zie voor een bespreking van deze Aanbevelingen: M.A. Fierstra, 'Nieuwe aanbevelingen voor het stellen van prejudiciële vragen', Trema 2017/2, p. 52-59. en dat de rechtmatigheid daarvan afhangt van het te geven antwoord op de prejudiciële vragen. ${ }^{10}$ Deze maatstaf is voor de nationale rechter het vertrekpunt bij de vraag of het nuttig is te verzoeken om toepassing van de spoedprocedure.

Opgemerkt moet worden dat het Hof van Justitie de situatie van de betrokkene beoordeelt zoals deze zich voordoet op de datum van het onderzoek van het verzoek om toepassing van de spoedprocedure. ${ }^{11}$ Deze beoordeling vindt dus plaats nadat de nationale rechter een dergelijk verzoek heeft gedaan. Als zich in de tussentijd wijzigingen kunnen voordoen in de situatie van de betrokkene (bijvoorbeeld een op handen zijnde invrijheidstelling of overdracht waar de nationale rechter van op de hoogte is), dan zal dat in de verwijzingsuitspraak tot uitdrukking moeten worden gebracht. Zo nodig kan het Hof van Justitie daarover nadere informatie inwinnen. ${ }^{12}$

Als op de datum van het onderzoek van een verzoek om toepassing van de spoedprocedure geen sprake (meer) is van vrijheidsontneming, dan zal dat verzoek worden afgewezen. Deze situatie doet zich bijvoorbeeld voor als een opgelegde vrijheidsstraf is omgezet in een voorwaardelijke straf en de betrokkene sindsdien voorwaardelijk in vrijheid is gesteld. ${ }^{13}$ Vrijheidsontneming was evenmin aan de orde in de zaak Bob-Dogi. Deze zaak betreft een Roemeens staatsburger die onder rechterlijk toezicht was geplaatst in het kader van strafvervolging wegens verdenking van het toebrengen van zwaar lichamelijk letsel. De verwijzende rechter meende dat dit toezicht moest worden aangemerkt als een maatregel die de individuele vrijheid van de betrokkene beperkte. Volgens het Hof van Justitie was echter geen sprake van vrijheidsontneming. ${ }^{14}$ Uit dit oordeel kan worden afgeleid dat een onderscheid moet worden gemaakt tussen vrijheidsbeneming en vrijheidsontneming. In het eerste geval wordt de bewegingsvrijheid van de betrokkene beperkt. Vrijheidsontneming gaat verder en impliceert gevangenzetting. Slechts in het laatste geval heeft het voor de nationale rechter zin om te verzoeken de spoedprocedure toe te passen.

De vraag rijst vervolgens wanneer wel sprake is van vrijheidsontneming. Dat is bijvoorbeeld het geval indien de betrokkene (al dan niet bij verstek) strafrechtelijk is veroordeeld en om die reden in detentie zit. Dit was aan de orde in de zaak Pustovarov, waarin de betrokkene in

10. HvJ 30 november 2009, zaak C-357/09 PPU, Kadzoev, ECLI:EU:C: 2009:741, punt 32; HvJ 28 april 2011, zaak C-61/11 PPU, El Dridi, ECLI:EU:C:2011:268, punt 27; HvJ 19 juli 2012, zaak C-278/12 PPU, Adil, ECLI:EU:C:2012:508, punt 34; HvJ 16 juli 2015, zaak C-237/15 PPU, Lanigan, ECLI:EU:C:2015:474, punt 24; HvJ 5 juli 2018, zaak C-269/18 PPU, C e.a., ECLI:EU:C:2018:544, punt 37.

11. HvJ 15 februari 2016, zaak C-601/15 PPU, N., ECLI:EU:C:2016:84, punt 40.

12. In dit verband is van belang dat het Hof van Justitie gemiddeld in iets meer dan acht dagen beslist op een binnengekomen verzoek om toepassing van de spoedprocedure. Zie het Report on the use of the urgent preliminary ruling procedure by the Court of Justice 2012, p. 6 en 12 (te raadplegen via www.curia.europa.eu).

13. HvJ 16 januari 2018, zaak C-240/17, E, ECLI:EU:C:2018:8, punt 31

14. HvJ 1 juni 2016 , zaak C-241/15, Bob-Dogi, ECLI:EU:C:2016:385, punten 27 en 28. 
Finland een gevangenisstraf uitzat voor verschillende strafbare feiten (waaronder het illegaal binnenbrengen van 26 kilogram hasjiesj) die de grondslag vormden voor de prejudiciële verwijzing. ${ }^{15}$ Daarnaast gelden voorlopige hechtenis en detentie in afwachting van de uitlevering aan een andere lidstaat of de tenuitvoerlegging van een Europees aanhoudingsbevel volgens het Hof van Justitie als strafrechtelijke vrijheidsontneming. ${ }^{16}$

Tot slot kan bestuursrechtelijke vrijheidsontneming voor de nationale rechter aanleiding zijn om te verzoeken de spoedprocedure toe te passen. Gedacht kan worden aan vreemdelingenrechtelijke bewaring van een asielzoeker. ${ }^{17}$ Ook bestuursrechtelijke bewaring ter fine van de uitzetting kan de toepassing van de spoedprocedure rechtvaardigen. Ik wijs in dit verband op de zaak Mahdi. Deze zaak betreft een gesteld Soedanees onderdaan die in Bulgarije in bewaring was gesteld in afwachting van de ontvangst van documenten waarmee hij buiten die lidstaat zou kunnen reizen. ${ }^{18}$

\section{Risico op onherstelbare beschadiging van de}

betrekkingen tussen kind en ouder

Het Hof van Justitie past de spoedprocedure ook toe op zaken waarin een risico bestaat op onherstelbare beschadiging van de betrekkingen tussen kind en ouder. ${ }^{19}$ Het is aan de nationale rechter om in het individuele geval te motiveren waarom dit aan de orde is. De jurisprudentie van het Hof van Justitie bevat hiertoe handvatten. Zo kan de nationale rechter erop wijzen dat een van de ouders het kind op onrechtmatige wijze naar een ander land heeft overgebracht. ${ }^{20}$ Daarnaast kunnen het bestaan van tegengestelde beslissingen of jurisdictiegeschillen in voogdijkwesties de relatie tussen het kind en een van zijn ouders onherstelbaar beschadigen. ${ }^{21}$ Voorts merkt het Hof van Justitie het ontbreken van elk contact tussen beiden aan als een omstandigheid die de toepassing van de spoedprocedure rechtvaardigt. ${ }^{22}$ Ook kan de nationale rechter wijzen op problemen die zullen ont-

15. HvJ 1 december 2008, zaak C-388/08 PPU, Pustovarov, ECLI:EU:C: 2008:669. Vgl. HvJ 28 april 2011, zaak C-61/11 PPU, El Dridi, ECLI:EU:C:2011:268.

16. HvJ 27 mei 2014, zaak C-129/14 PPU, Spasic, ECLI:EU:C:2014:586; HvJ 12 augustus 2008, zaak C-296/08 PPU, Santesteban Goicoechea, ECLI:EU:C:2008:457; HvJ 28 juni 2012, zaak C-192/12 PPU, West, ECLI:EU:C:2012:404.

17. HvJ 17 maart 2016, zaak C-695/15 PPU, Mirza, ECLI:EU:C:2016:188.

18. HvJ 5 juni 2014, zaak C-146/14, Mahdi, ECLI:EU:C:2014:1320. Vgl. HvJ 10 september 2013, zaak C-383/13 PPU, G. en R., ECLI:EU:C: 2013:533, punten 23 en 25.

19. Deze maatstaf wordt genoemd in het eerder aangehaalde Report on the use of the urgent preliminary ruling procedure by the Court of Justice (p. 7) en in Bartolini 2018, p. 218. Deze maatstaf lijkt afkomstig uit HvJ 23 december 2009, zaak C-403/09 PPU, Deticek, ECLI:EU:C: 2009:810, punt 30. Zie verder HvJ 11 juli 2008, zaak C-195/08 PPU, Rinau, ECLI:EU:C:2008:406; HvJ 1 juli 2010, zaak C-211/10 PPU, Povse, ECLI:EU:C:2010:400; HvJ 22 december 2010, zaak C-497/10 PPU, Mercredi, ECLI:EU:C:2010:829; HvJ 9 oktober 2014, zaak C-376/14 PPU, C, ECLI:EU:C:2014:2268.

20. HvJ 11 juli 2008, zaak C-195/08, Rinau, ECLI:EU:C:2008:406; HvJ 10 april 2018, zaak C-85/18 PPU, CV/DU, ECLI:EU:C:2018:220.

21. HvJ 23 december 2009, zaak C-403/09 PPU, Deticek, ECLI:EU:C: 2009:810; HvJ 9 januari 2015, zaak C-498/14, Bradbrooke, ECLI:EU:C: 2015:3.

22. HvJ 1 juli 2010, zaak C-211/10 PPU, Povse, ECLI:EU:C:2010:400. staan bij de integratie van het jonge kind in zijn nieuwe familiale en sociale omgeving. ${ }^{23}$

Overige omstandigheden

Recente jurisprudentie laat zien dat het Hof van Justitie ook in andere dan de hierboven beschreven omstandigheden bereid is de spoedprocedure toe te passen. Dit is bijvoorbeeld het geval indien sprake is van omstandigheden waarin de betrokkenen een risico lopen te worden onderworpen aan onmenselijke of vernederende behandelingen. Dat was het geval in de zaak $X$ en $X$. Deze zaak betrof een weigering visa met territoriaal beperkte geldigheid af te geven. De nationale rechter had onder meer gewezen op de dramatische situatie van het gewapende conflict in Syrië, de jonge leeftijd van de kinderen van de betrokkenen, het feit dat zij bijzonder kwetsbaar waren en het feit dat de zaak bij de nationale rechter aanhangig was gemaakt in het kader van een procedure tot schorsing bij uiterst dringende noodzakelijkheid. Dit een en ander moest volgens het Hof van Justitie worden aangemerkt als een element dat de toepassing van de spoedprocedure rechtvaardigde. ${ }^{24}$

Dit voorbeeld laat zien dat de toepassing van de spoedprocedure niet is beperkt tot vrijheidsontneming en het bestaan van een risico op onherstelbare beschadiging van de betrekkingen tussen kind en ouder. De nationale rechter kan dus ook in andere gevallen om toepassing van die procedure verzoeken. Bij de afweging daartoe zal hij de op het spel staande rechten en belangen moeten betrekken en moeten beargumenteren waarom deze door tijdsverloop onherstelbaar kunnen worden geschaad (zie hiervoor, paragraaf Kenmerken).

\section{PPA: de versnelde procedure}

\section{Kenmerken ${ }^{25}$}

De versnelde procedure bestaat sinds 1 februari 2001 en is daarmee ouder dan de spoedprocedure. De president van het Hof van Justitie kan, op verzoek van de verwijzende rechter of, bij wijze van uitzondering, ambtshalve, beslissen een prejudiciële verwijzing volgens de versnelde procedure te behandelen. Daarvoor moet de aard van de zaak een behandeling binnen korte termijnen vereisen (art. 105 lid 1 van het Reglement). Als de president beslist tot toepassing van de versnelde procedure, dan bepaalt hij onmiddellijk de datum van de terechtzitting, die aan de belanghebbenden wordt meegedeeld bij de betekening van het verzoek om een prejudiciële beslissing (lid 2).

De versnelde procedure is niet beperkt tot de ruimte van vrijheid, veiligheid en recht. Dit betekent dat de nationale rechter in alle domeinen van het Unierecht kan verzoeken om de versnelde procedure toe te passen

23. HvJ 17 oktober 2018, zaak C-393/18 PPU, UD/XB, punten 23, 24 en 26.

24. HvJ 7 maart 2017, zaak C-638/16 PPU, $X$ en X, ECLI:EU:C:2017:173, punten 30 en 33

25. Zie uitgebreider: Wathelet 2014, p. 34-37, 39-45. 
en dat de president van het Hof van Justitie deze procedure in al die domeinen ambtshalve kan toepassen. Dit geldt dus ook voor een prejudiciële verwijzing die wel onder vorenbedoelde ruimte valt, maar waarin de toepassing van de spoedprocedure niet is aangewezen. ${ }^{26}$

Omstandigheden die geen versnelde procedure rechtvaardigen

De nationale rechter moet uiteenzetten waarom de aard van de zaak toepassing van de versnelde procedure verlangt. ${ }^{27}$ De enkele omstandigheid dat de nationale procedure een urgent karakter heeft of dat die rechter gehouden is snel in de bodemprocedure uitspraak te doen, is volgens het Hof van Justitie onvoldoende. ${ }^{28} \mathrm{Dit}$ geldt ook voor de juridische onzekerheid waarin de betrokkene, bijvoorbeeld een gezocht persoon, ${ }^{29}$ een asielzoeker ${ }^{30}$ of minderjarig kind, ${ }^{31}$ kan verkeren. Meer in het algemeen kan een belang van de rechtzoekende om zo snel mogelijk te weten of, en zo ja, in hoeverre, hij rechten aan het Unierecht kan ontlenen, op zichzelf niet tot toepassing van de versnelde procedure leiden. ${ }^{32}$ Voorts rechtvaardigen het aantal personen dat eventueel geraakt wordt door de beslissing van het Hof van Justitie en het aantal zaken dat de nationale rechter na die beslissing zal moeten afdoen op zichzelf niet de toepassing van de versnelde procedure. ${ }^{33}$ Eenzelfde redenering wordt gehanteerd bij het bestaan van divergerende nationale jurisprudentie ${ }^{34}$ en economische belangen. ${ }^{35}$ Daarnaast kan een tijdspanne tussen de datum waarop de verwijzingsbeslissing is gedaan en die waarop zij aan

26. Bijv. HvJ 15 juli 2010, zaak C-296/10, Purrucker, ECLI:EU:C:2010:665; HvJ 10 oktober 2011, zaak C-300/11, ZZ, ECLI:EU:C:2013:363; HvJ 3 juli 2015, zaak C-215/15, Gogova, ECLI:EU:C:2015:710.

27. Aanbevelingen aan de nationale rechterlijke instanties over het aanhangig maken van prejudiciële procedures (2016/C 439/01), punt 33. Zie ook HvJ 18 juli 2013, zaak C-42/13, Cartiera dell'Adda, ECLI:EU:C: 2013:508, punt 11; HvJ 28 november 2013, zaak C-396/13, SähköaIojen ammattiliitto, ECLI:EU:C:2013:811, punt 14. Een simpele verwijzing naar de motivering van het verzoek om een prejudiciële beslissing volstaat dus niet. Zie HvJ 3 juli 2018, zaak C-305/18, Associazione Verdi Ambiente e Società - Aps Onlus e.a., ECLI:EU:C:2018:549, punten 10 en 11

28. Bijv. HvJ 17 november 2004, gevoegde zaken C-363/04 tot C-365/04, Michaniki, ECLI:EU:C:2004:843, punt 7; HvJ 3 april 2007, zaak C-33/07, Jipa, ECLI:EU:C:2007:210, punt 7; HvJ 7 oktober 2013, zaak C-392/13, Rabal Cañas, ECLI:EU:C:2015:318, punt 15; HvJ 25 januari 2017, zaak C-647/16, Hassan, ECLI:EU:C:2018:368, punt 12; HvJ 25 juli 2018, zaak C-333/18, Lombardi, ECLI:EU:C:2018:629, punt 9.

29. HvJ 23 december 2015, zaak C-640/15, Vilkas, ECLI:EU:C:2017:39, punt 10.

30. HvJ 5 oktober 2012, zaak C-394/12, Abdullahi, ECLI:EU:C:2013:813, punt 14.

31. HvJ 13 januari 2015, zaak C-489/14, A, ECLI:EU:C:2015:654, punt 20.

32. HvJ 28 november 2013, zaak C-396/13, Sähköalojen ammattiliitto, ECLI:EU:C:2013:811, punt 16; HvJ 8 maart 2018, zaak C-63/18, Vitali SpA, ECLI:EU:C:2018:199, punt 18

33. HvJ 10 januari 2012, zaak C-534/11, Arslan, ECLI:EU:C:2013:343, punten 10 en 12; HvJ 5 oktober 2012, zaak C-394/12, Abdullahi, ECLI:EU:C:2013:813, punt 11; HvJ 25 juli 2018, zaak C-333/18, Lombardi, ECLI:EU:C:2018:629, punt 7.

34. HvJ 30 april 2018, zaak C-185/18, Oro Efectivo SL, ECLI:EU:C: 2018:298, punt 17

35. HvJ 3 juli 2008, zaak C-201/08, Plantanol, ECLI:EU:C:2008:385, punt 9; HvJ 29 januari 2014, zaak C-436/13, E., ECLI:EU:C:2014:95, punt 27; HvJ 2 september 2015, zaak C-353/15, Leonmobili en Leone, ECLI:EU:C:2016:374, punt 8 het Hof van Justitie is voorgelegd, afbreuk doen aan de noodzaak tot toepassing van de versnelde procedure. Dit was bijvoorbeeld aan de orde in de zaak Pontini e.a. De nationale rechter had zijn verwijzingsbeslissing op 8 mei 2008 uitgesproken, terwijl deze beslissing pas op 18 augustus 2008 bij het Hof van Justitie was binnengekomen. ${ }^{36}$

Omstandigheden die wel een versnelde procedure rechtvaardigen

De nationale rechter kan er bij het verzoek om toepassing van de versnelde procedure op wijzen dat zijn prejudiciële vragen betrekking hebben op een domein dat essentieel en gevoelig is voor de activiteiten van de EU. Dit is bijvoorbeeld het geval bij prejudiciële vragen in het kader van de strijd tegen terrorisme. ${ }^{37}$ Ook als langdurige onzekerheid over de uitkomst van de prejudiciële procedure het functioneren van een door Unierecht ingesteld systeem kan belemmeren (bijvoorbeeld het Europees asielbeleid), is het nuttig te verzoeken om toepassing van de versnelde procedure. ${ }^{38}$

Voorts kunnen ernstige onzekerheden ten aanzien van fundamentele kwesties van nationaal staatsrecht en Unierecht voor de nationale rechter aanleiding zijn om toepassing van de versnelde procedure te verzoeken. Die rechter moet dan wel de specifieke omstandigheden uiteenzetten waaruit die onzekerheden blijken. Zo wees de Schotse rechter in de zaak Wightman e.a., die ging over de vraag of het Verenigd Koninkrijk zijn uitgesproken intentie om uit de EU te treden ('Brexit') unilateraal ongedaan kan maken, erop dat de termijn van twee jaren waaraan de procedure tot uittreding is onderworpen, op 29 maart 2017 was begonnen. Ook onderstreepte die rechter de noodzaak om voorafgaand aan 29 maart 2019 nationale debatten en stemmingen over een uittreding te organiseren. Het Hof van Justitie oordeelde dat van belang was dat de Britse parlementariërs zekerheid hadden over de reikwijdte van artikel 50 VEU voordat zij zich over een akkoord zouden uitspraken, zodat om die reden toepassing van de versnelde procedure gerechtvaardigd was. ${ }^{39}$

De nationale rechter kan er ook op wijzen dat de betrokkene in een vorm van detentie zit die niet onder de ruimte van vrijheid, veiligheid en recht valt. ${ }^{40}$ Daarnaast kan de juridische onzekerheid waarin de betrokkene ver-

36. HvJ 29 september 2008, zaak C-375/08, Pontini e.a., ECLI:EU:C: 2008:528, punt 10

37. HvJ 1 maart 2010, zaak C-550/09, E en F, ECLI:EU:C:2010:103, punt 10.

38. HvJ 15 februari 2017, zaak C-670/16, Mengesteab, ECLI:EU:C: 2017:120, punt 13. Vgl. HvJ 22 februari 2008, zaak C-66/08, Kozlowski, ECLI:EU:C:2008:116, punt 11; HvJ 15 februari 2017, zaak C-646/16, Jafari, ECLI:EU:C:2017:138, punt 11

39. HvJ 19 oktober 2018, zaak C-621/18, Wightman e.a., ECLI:EU:C: 2018:851, punten 8-10 met verwijzing naar HvJ 28 februari 2017, zaak C-42/17, M.A. S. en M.B., ECLI: EU:C:2017:168, punt 9; HvJ 26 september 2018, zaak C-522/18, Zakład Ubezpieczeń Społecznych, ECLI:EU:C:2018:786, punt 15

40. HvJ 6 mei 2014, zaak C-181/14, G., ECLI:EU:C:2014:740, punt 10 (over Richtlijn 2001/83/EG tot vaststelling van een communautair wetboek betreffende geneesmiddelen voor menselijk gebruik). De betrokkene zat een gevangenisstraf uit wegens verkoop van kruidenmengsels met synthetische cannabinoïdes. 
keert wel aanleiding zijn de versnelde procedure toe te passen, indien die onzekerheid de uitoefening van een normaal familieleven belemmert. ${ }^{41}$ Dit geldt ook voor het bestaan van eventuele (andere) ernstige inbreuken op de fundamentele rechten uit het EU-Handvest, zoals het bewaren krachtens nationale regels van gegevens over elektronische communicatie. ${ }^{42}$

\section{Behandeling met voorrang}

Naast de spoedprocedure en de versnelde procedure beschikt het Hof van Justitie nog over een derde mechanisme om de behandeling van een prejudiciële verwijzing te versnellen. Het gaat om de behandeling met voorrang. Dit mechanisme is opgenomen in artikel 53 lid 3 van het Reglement. Op grond van die bepaling kan de president van het Hof van Justitie wegens bijzondere omstandigheden beslissen dat een zaak met voorrang wordt behandeld. In de praktijk betekent dit dat het dossier zo veel mogelijk 'bovenop de stapel' wordt gelegd. ${ }^{43}$

Beslissingen tot het behandelen van een prejudiciële verwijzing met voorrang worden niet gemotiveerd. Soms verwijst het Hof van Justitie voor de motivering slechts naar 'de omstandigheden in het hoofdgeding'. ${ }^{44}$ Evenmin lijken deze beslissingen te worden gepubliceerd. Een verwijzing hiernaar heb ik uitsluitend aangetroffen in de prejudiciële arresten. ${ }^{45}$ Dit maakt het ingewikkeld om helder te krijgen wat met vorenbedoelde 'bijzondere omstandigheden' wordt bedoeld.

Opvallend is dat het Hof van Justitie vooral geneigd lijkt om prejudiciële verwijzingen met voorrang te behandelen als zij vallen onder de ruimte van vrijheid, veiligheid en recht, en de spoedprocedure uitdrukkelijk niet van toepassing wordt geacht. Zo heeft de president van het Hof van Justitie besloten om zaken over de Terugkeerrichtlijn, ${ }^{46}$ Kaderbesluit $2002 / 584 / \mathrm{JBZ}^{47}$, de Dublin

41. HvJ 17 april 2008, zaak C-127/08, Metock e.a., ECLI:EU:C:2008:235, punt 16; HvJ 9 september 2011, zaak C-256/11, Dereci e.a., ECLI:EU:C:2011:571, punten 16 en 17.

42. HvJ 1 februari 2016, zaak C-698/15, Watson e.a., ECLI:EU:C:2016:70, punt 11.

43. Vgl. Wathelet 2014, p. 37-38.

44. HvJ 16 januari 2018, zaak C-240/17, E, ECLI:EU:C:2018:8, punt 32; HvJ 25 juli 2018, zaak C-268/17, AY, ECLI:EU:C:2018:602, punt 22.

45. HvJ 8 januari 2014, vermeld in HvJ 12 november 2014, zaak C-656/13, L, ECLI:EU:C:2014:2364, punt 33; HvJ 30 juni 2015, vermeld in HvJ 1 juni 2016, zaak C-241/15, Bob-Dogi, ECLI:EU:C:2016:385, punt 29; HvJ 12 juni 2017, vermeld in HvJ 16 januari 2018, zaak C-240/17, E, ECLI:EU:C:2018:8, punt 32. Zie voor een uitzondering: HvJ 10 mei 2017, zaak C-133/15, Chavez-Vilchez e.a., ECLI:EU:C:2017:354. Slechts A-G Szpunar maakt in zijn conclusie melding van een beslissing tot behandeling met voorrang (8 september 2016, ECLI:EU:C: 2016:659, punt 37). In het prejudicieel arrest wordt hier niet over gerept.

46. Richtlijn 2008/115/EG van het Europees Parlement en de Raad van 16 december 2008 over gemeenschappelijke normen en procedures in de lidstaten voor de terugkeer van onderdanen van derde landen die illegaal op hun grondgebied verblijven, PbEU 2008, L 348/98-107.

47. Kaderbesluit 2002/584/JBZ van de Raad van 13 juni 2002 betreffende het Europees aanhoudingsbevel en de procedures van overlevering tussen de lidstaten, PbEG 2002, L 190/1-20.
III-verordening en Verordening (EG) nr. 2201/2003 $3^{48}$ aldus te behandelen. De eerstbedoelde zaak betreft een beslissing van de Finse autoriteiten om de betrokkene terug te sturen naar Nigeria, terwijl hij een verblijfsrecht in Spanje had. ${ }^{49}$ In de zaak over Kaderbesluit 2002/584/JBZ ging het om een betrokkene tegen wie een voorlopige hechtenis was uitgesproken en die elk moment kon worden aangehouden. ${ }^{50}$ In de derde genoemde zaak weigerden de Sloveense autoriteiten een asielaanvraag in behandeling te nemen, omdat Kroatië daarvoor verantwoordelijk zou zijn. ${ }^{51}$ Tot slot ging het in de zaak over Verordening (EG) nr. 2201/2003 om de vraag of de Oostenrijkse of de Tsjechische rechter bevoegd was zich uit te laten over een voogdij- en alimentatieverzoek. ${ }^{52}$ Kennelijk zijn dit bijzondere omstandigheden die een behandeling met voorrang rechtvaardigen.

Ook in zaken die niet vallen onder de ruimte van vrijheid, veiligheid en recht kan de nationale rechter om een behandeling met voorrang verzoeken. Ik wijs bijvoorbeeld op de prejudiciële vragen van de Afdeling bestuursrechtspraak van de Raad van State over het Programma Aanpak Stikstof, waarin zij had verzocht om behandeling met voorrang vanwege de grote gevolgen voor de economie en de natuurgebieden in Nederland. ${ }^{53}$ Het Hof van Justitie heeft dit verzoek ingewilligd en op 7 november 2018 arrest gewezen. ${ }^{54}$

\section{Conclusies}

Deze bijdrage gaat over de vraag welke criteria worden gehanteerd bij de beslissing tot toepassing van de spoedprocedure, de versnelde procedure en de behandeling met voorrang. Deze drie mechanismen wijken af van de standaardprocedure die het Hof van Justitie toepast op de behandeling van een prejudiciële verwijzing. Voor de nationale rechter is een antwoord op de gestelde vraag van belang om te kunnen bepalen of het nuttig is te verzoeken tot toepassing van (een van) deze drie mechanismen.

Op basis van een analyse van de jurisprudentie van het Hof van Justitie kunnen over de spoedprocedure de volgende conclusies worden getrokken. Voorop moet worden gesteld dat deze procedure uitsluitend kan worden ingeleid voor prejudiciële verwijzingen die betrekking

48. Verordening (EG) nr. 2201/2003 van de Raad van 27 november 2003 betreffende de bevoegdheid en de erkenning en tenuitvoerlegging van beslissingen in huwelijkszaken en inzake de ouderlijke verantwoordelijkheid, en tot intrekking van Verordening (EG) nr. 1347/2000, PbEU 2003, L 338/1-29.

49. HvJ 16 januari 2018, zaak C-240/17, E, ECLI:EU:C:2018:8.

50. HvJ 25 juli 2018, zaak C-268/17, AY, ECLI:EU:C:2018:602; HvJ 1 juni 2016, zaak C-241/15, Bob-Dogi, ECLI:EU:C:2016:385.

51. HvJ 26 juli 2017, zaak C-490/16, A.S., ECLI:EU:C:2017:585.

52. HvJ 12 november 2014, zaak C-656/13, L., ECLI:EU:C:2014:2364.

53. ABRvS 17 mei 2017, ECLI:NL:RVS:2017:1259 en ECLI:NL:RVS: 2017:1260

54. HvJ 7 november 2018, gevoegde zaken C-293/17 en C-294/17, Coöperatie Mobilisation for the Environment e.a., ECLI:EU:C: 2018:882, punt 58 . 
hebben op de ruimte van vrijheid, veiligheid en recht. Voorts kan de nationale rechter als maatstaf hanteren dat sprake moet zijn van een situatie waarin de op het spel staande rechten en belangen onherstelbaar door tijdsverloop kunnen worden geschaad. In dit verband kan hij erop wijzen dat de betrokkene straf- of bestuursrechtelijk van zijn vrijheid is ontnomen of dat een risico bestaat op onherstelbare beschadiging van de relatie tussen kind en ouder. Daarnaast kan de spoedprocedure in andere gevallen worden toegepast, bijvoorbeeld op zaken waarin de betrokkenen een risico lopen te worden onderworpen aan onmenselijke of vernederende behandelingen.

Voor de versnelde procedure kan worden geconcludeerd dat een aantal omstandigheden op zichzelf niet tot toepassing van deze procedure kan leiden. Het gaat bijvoorbeeld om de juridische onzekerheid waarin de betrokkene verkeert of het aantal personen dat eventueel geraakt wordt door de beslissing van het Hof van Justitie. Daarentegen kan het voor de nationale rechter nuttig zijn om toepassing van de versnelde procedure te verzoeken, als zijn prejudiciële vragen betrekking hebben op een domein dat essentieel en gevoelig is voor de activiteiten van de Europese Unie, als het functioneren van een door Unierecht ingesteld systeem wordt belemmerd of als er ernstige onzekerheden bestaan ten aanzien van fundamentele kwesties van nationaal staatsrecht en Unierecht. Ook een detentie die niet onder de ruimte van vrijheid, veiligheid en recht valt en het bestaan van ernstige inbreuken op de fundamentele rechten uit het EU-Handvest zijn voor de nationale rechter argumenten om de toepassing van de versnelde procedure te verzoeken.

Tot slot kan het Hof van Justitie een prejudiciële verwijzing met voorrang behandelen. In de praktijk betekent dit dat het dossier zo veel mogelijk 'bovenop de stapel' wordt gelegd. Beslissingen over het al dan niet behandelen met voorrang worden niet gemotiveerd en lijken evenmin te worden gepubliceerd. Dit maakt het ingewikkeld om op dit punt conclusies te trekken. In elk geval valt op dat het Hof van Justitie vooral geneigd lijkt om prejudiciële verwijzingen met voorrang te behandelen als zij vallen onder de ruimte van vrijheid, veiligheid en recht, en de spoedprocedure uitdrukkelijk niet van toepassing wordt geacht. 